\title{
Canonical Analysis Technique as an Approach to Determine Optimal Conditions for Lactic Acid Production by Lactobacillus helveticus ATCC 15009
}

\author{
Marcelo Teixeira Leite, ${ }^{1}$ Marcos Antonio de Souza Barrozo, ${ }^{2}$ and Eloizio Júlio Ribeiro ${ }^{2}$ \\ ${ }^{1}$ Center of Technology and Regional Development, Federal University of Paraíba, 58051-900 João Pessoa, PB, Brazil \\ ${ }^{2}$ Chemical Engineering College, Federal University of Uberlândia, 38408-100 Uberlândia, Brazil \\ Correspondence should be addressed to Marcelo Teixeira Leite, leitemarcelo@terra.com.br
}

Received 26 June 2011; Revised 8 October 2011; Accepted 25 October 2011

Academic Editor: Iftekhar A. Karimi

Copyright (C) 2012 Marcelo Teixeira Leite et al. This is an open access article distributed under the Creative Commons Attribution License, which permits unrestricted use, distribution, and reproduction in any medium, provided the original work is properly cited.

\begin{abstract}
The response surface methodology and canonical analysis were employed to find the most suitable conditions for Lactobacillus helveticus to produce lactic acid from cheese whey in batch fermentation. The analyzed variables were temperature, $\mathrm{pH}$, and the concentrations of lactose and yeast extract. The experiments were carried out according to a central composite design with three center points. An empiric equation that correlated the concentration of lactic acid with the independent variables was proposed. The optimal conditions determined by the canonical analysis of the fitted model were $40^{\circ} \mathrm{C}, \mathrm{pH} 6.8,82 \mathrm{~g} / \mathrm{L}$ of lactose, and $23.36 \mathrm{~g} / \mathrm{L}$ of yeast extract. At this point, the lactic acid concentration reached $59.38 \mathrm{~g} / \mathrm{L}$. A subsequent fermentation, carried out under optimal conditions, confirmed the product concentration predicted by the adjusted model. This concentration of lactic acid is the highest ever reported for Lactobacillus helveticus ATCC 15009 in batch process using cheese whey as substrate.
\end{abstract}

\section{Introduction}

1.1. Cheese Whey as a Pollutant. Cheese whey is the liquid remaining after the precipitation and removal of milk casein during cheese making. This byproduct represents $85-90 \%$ of the milk volume and retains $55 \%$ of milk nutrients. Among the most abundant of these nutrients are lactose (4.5$5.0 \% \mathrm{w} / \mathrm{v})$, soluble proteins $(0.6-0.8 \% \mathrm{w} / \mathrm{v})$, lipids, and mineral salts [1]. It is produced in large amounts by the dairy industry. To produce $1 \mathrm{~kg}$ of cheese are produced, on average, $9 \mathrm{~kg}$ of whey.

Because it is a byproduct of low economic value, formerly the cheese whey was simply dumped in watercourses without any previous treatment. This caused the whey to become a serious environmental problem due to its high content of organic matter, with $\mathrm{BOD}=30,000-50,000 \mathrm{mg} / \mathrm{L}$ and $\mathrm{COD}=$ $60,000-80,000 \mathrm{mg} / \mathrm{L}[2]$.

1.2. Cheese Whey as a Resource. The whey produced in the dairy industry has two destinations: disposal or utilization. Disposal here means launching over the field, pumping in water courses, and treatment in effluent systems. In the first case, the use of whey as a fertilizer can over time unduly increase soil salinity. The pumping of untreated whey in watercourses is an environmentally incorrect solution and it is banned in several countries.

Although it solves the legal problems associated with the launch in watercourses, treating whey as an effluent increases production costs and brings no economic return to the producer $[3,4]$.

The recovery of nutrients from whey and its transformation into higher value-added compounds are better alternatives than the disposal. Thus, it is possible to have a parallel economic activity to reduce the polluting effect. The organic component available in the whey can be used in various ways.

The proteins can be separated by ultrafiltration and used as food supplement and raw material to manufacture nutritional products [5]. However, the recovery of the proteins little contributes to the decrease of the polluting load of the whey, consisted mainly of the lactose present in the permeated. Therefore, the study of the several possibilities to 
use this sugar is of great interest. One of the most promising alternatives is to use it as a source of low cost carbon, for the production of organic acids by fermentation. Most of the researches developed in the last years seek the production of lactic acid of high-added value, through the fermentation of the lactose present in the whey [6].

1.3. The Lactic Acid. Lactic acid is a versatile product that finds applications in several areas. It is used as acidulant in the food, cosmetics, and pharmaceutical industries [7]. Its isomers $L(+)$ and $D(-)$ can be polymerized to obtain compounds with different properties, depending on their intended application. In the medical area, the lactic acid has been used in the production of biodegradable polymers, used as scaffold in tissue transplants $[8,9]$. The lactic acid polymers are also used in the production of biodegradable packages [10].

From the amount of lactic acid produced annually all over the world, about $90 \%$ is obtained by fermentation. The rest is synthesized starting from the hydrolysis of the lactonitrile. The production of lactic acid by fermentation presents advantages. One of them is the possibility to use renewable substrate, such as starch and cellulose. Another great advantage is that some strains can produce pure forms $L(+)$ or $D(-)$, while the chemical course always takes to the formation of a racemic mixture. The most commonly used substrates for the fermentative production of lactic acid are cheese whey, molasses, and starch. Before its use in fermentative processes, the whey must be deproteinized and demineralized. The separation of the proteins is usually made by ultrafiltration. Yeast extract, peptone, powder milk, and soybean meal are used as supplements in the fermentation of the whey. The microorganisms most frequently used are Lactobacillus bulgaricus, Lactobacillus helveticus, Lactobacillus delbrueckii, and Lactobacillus casei [11].

1.4. Canonical Analysis. Nowadays, most of the studies over the fermentative production of lactic acid have the process optimisation as a goal. The experiments are designed to find better media for growth and fermentation, besides optimum values for process variables such as $\mathrm{pH}$ and temperature. Several researchers have been using the response surface methodology (RSM) to achieve these goals. Hujanen et al. [12] studied the optimisation of the production of lactic acid using Lactobacillus casei. The optimum operating conditions were obtained at $35^{\circ} \mathrm{C}$ and $\mathrm{pH}$ 6.3. Téllez-Luis et al. [13] and Bustos et al. [10] studied the optimisation of a low cost fermentation medium, made up of corn steep liquor supplemented with peptone and yeast extract. Naveena et al. [14] achieved the optimisation of a solid medium made with wheat bran to produce lactic acid using Lactobacillus amylophilus. However, the authors of all these works did not use the canonical analysis to find the point of maximum response.

Canonical correlation analysis is a multivariate statistical model that facilitates the study of interrelationships among sets of multiple dependent variables and multiple independent variables. Whereas multiple regression predicts a single dependent variable from a set of multiple independent
TABLE 1: Coded and actual values of the central composite design.

\begin{tabular}{lccccc}
\hline & & \multicolumn{5}{c}{$X_{i}$} \\
& -1.55 & -1 & 0 & 1 & 1.55 \\
\hline $\mathrm{LC}(\mathrm{g} / \mathrm{L})$ & 46.8 & 55 & 70 & 85 & 93.2 \\
$\mathrm{YE}(\mathrm{g} / \mathrm{L})$ & 0 & 4.37 & 12.37 & 20.37 & 24.74 \\
$T\left({ }^{\circ} \mathrm{C}\right)$ & 33.8 & 36 & 40 & 44 & 46.2 \\
$\mathrm{pH}$ & 4.5 & 5 & 6 & 7 & 7.5 \\
\hline
\end{tabular}

variables; canonical correlation simultaneously predicts multiple dependent variables from multiple independent variables. Canonical correlation places the fewest restrictions on the types of data on which it operates. Because the other techniques impose more rigid restrictions, it is generally believed that the information obtained from them is of higher quality and may be presented in a more interpretable manner. For this reason, many researchers view canonical correlation as a last-ditch effort to be used when all other higher-level techniques have been exhausted. But in situations with multiple dependent and independent variables, canonical correlation is the most appropriate and powerful multivariate technique [15]. This technique has been used successfully in several studies on process optimization $[16,17]$. It has gained acceptance in many fields and represents a useful tool for multivariate analysis, particularly as interest has spread to considering multiple dependent variables.

The objective of the present work was to use the response surface methodology and canonical analysis to find the most suitable conditions for Lactobacillus helveticus ATCC 15009 to produce lactic acid from cheese whey in batch fermentation. The influences of four process variables have been studied: temperature, $\mathrm{pH}$, and the concentrations of lactose and yeast extract. Lactobacillus helveticus (ATCC 15009) has been chosen because it appears to be the most productive bacteria for lactic acid production from lactose [18]. The experiments were carried out according to a central composite design with three center points. The point of maximum response was obtained through a canonical analysis of the adjusted response surface [19].

\section{Material and Methods}

2.1. Inoculum and Fermentation Medium. Lactobacillus helveticus ATCC 15009 was supplied by the André Tosello Foundation (Campinas, SP, Brazil). Stock cultures were maintened on MRS broth [20] and deep frozen at $-18^{\circ} \mathrm{C}$. As required, these cultures were thawed and reactivated by two transfers in MRS broth $\left(24 \mathrm{~h}, 37^{\circ} \mathrm{C}, 120 \mathrm{rpm}\right)$. The cellular concentration of the inoculum was of $1.0 \times 10^{7}$ cells $/ \mathrm{mL}$.

The fermentation medium was made up of deproteinized reconstituted cheese whey, supplemented with yeast extract. The concentrations of lactose (LC) and yeast extract (YE) used are shown in Table 1.

2.2. Fermentations and Analyses. Batch fermentations were carried out at $150 \mathrm{rpm}$ for 32 hours under anaerobic conditions in a $3.0 \mathrm{~L}$ fermentor NBS Bioflo 110 (New Brunswick Scientific, USA), in which $1800 \mathrm{~mL}$ of sterile culture medium 
was inoculated with $200 \mathrm{~mL}$ of seed culture at $1.0 \times 10^{7}$ cells/ $\mathrm{mL}$. The $\mathrm{pH}$ was maintained at desired values by automatic addition of $6.0 \mathrm{~N} \mathrm{NaOH}$.

Lactic acid concentration was determined by a lactate analyzer, Accutrend Lactate (Roche, Germany). In this equipment, the lactic acid is measured by reflectance photometry, after a reaction between lactate and lactate-oxidase. The lactose was quantified using the 3.5-dinitrosalicylic acid method [21]. Biomass measurements were estimated from OD readings at $650 \mathrm{~nm}$. The samples were centrifuged, washed twice with deionized water, and then rediluted, before being introduced in the spectrophotometer. By means of a calibration curve $\left(X=\mathrm{OD}_{650} / 2.35\right)$, OD readings were converted to grams of dry cell per $\mathrm{mL}$.

2.3. Experimental Design. The experiments were carried out according to a central composite design with three center points, leading to a set of 27 experiments. The independent variables were lactose concentration (LC), yeast extract concentration (YE), temperature $(T)$, and $\mathrm{pH}$. The chosen value for the extreme level of the design was $\alpha=1.55$. This value was selected in order to obtain an orthogonal design, where the variance and covariance matrix is diagonal and the estimated parameters are not correlated amongst themselves. The coded (dimensionless) variables were defined as

$$
\begin{gathered}
x_{1}=\frac{\mathrm{LC}(\mathrm{g} / \mathrm{L})-70 \mathrm{~g} / \mathrm{L}}{15 \mathrm{~g} / \mathrm{L}}, \\
x_{2}=\frac{\mathrm{YE}(\mathrm{g} / \mathrm{L})-12.37 \mathrm{~g} / \mathrm{L}}{8 \mathrm{~g} / \mathrm{L}}, \\
x_{3}=\frac{T\left({ }^{\circ} \mathrm{C}\right)-40^{\circ} \mathrm{C}}{4{ }^{\circ} \mathrm{C}}, \\
x_{4}=\mathrm{pH}-6,
\end{gathered}
$$

where $x_{1}, x_{2}, x_{3}$, and $x_{4}$ are coded variables related to lactose concentration, yeast extract concentration, temperature, and $\mathrm{pH}$, respectively. The levels used to code these variables are in Table 1. The variables range was selected on the basis of previous works [11].

2.4. Canonical Analysis. To quantify the effects of independent variables and their interactions, an empirical equation was fitted to the experimental data. This second order equation can be represented by matricial notation as

$$
\hat{y}=b_{0}+x^{\prime} b+x^{\prime} B x,
$$

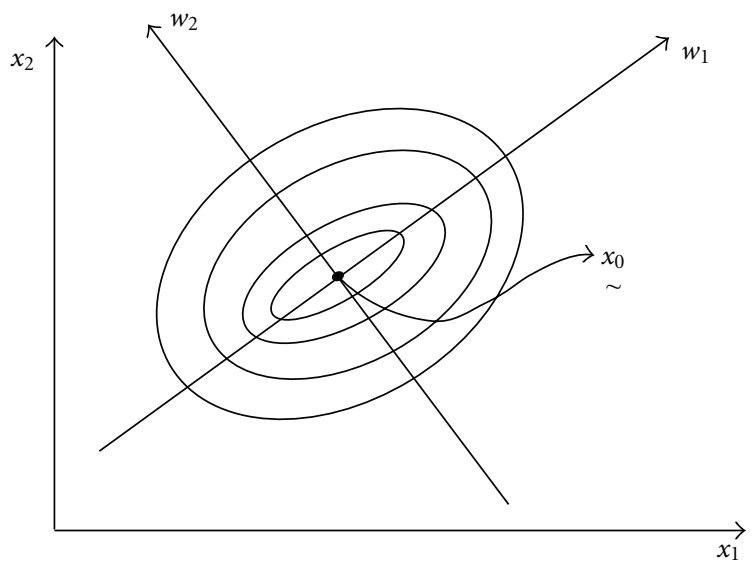

Figure 1: Graphical representation of axis translation.

where $\hat{y}$ is the predicted response, $\mathbf{x}=\left[\begin{array}{c}x_{1} \\ x_{2} \\ \vdots \\ x_{k}\end{array}\right]$ is the independent variables vector, $\mathbf{b}=\left[\begin{array}{c}b_{1} \\ b_{2} \\ \vdots \\ b_{k}\end{array}\right]$ is the parameters vector of the first order terms, and

$$
B=\left[\begin{array}{cccc}
b_{11} & \frac{b_{12}}{2} & \cdots & \frac{b_{1 k}}{2} \\
\frac{b_{21}}{2} & b_{22} & \cdots & \frac{b_{2 k}}{2} \\
\cdots & & \cdots & \cdots \\
& & \cdots & \frac{b_{k-1, k}}{2} \\
& & & b_{k k}
\end{array}\right]
$$

is the parameters matrix of the quadratic terms.

The expected maximum for the response (lactic acid concentration in this case), if it exists, will be a set of conditions $\left(x_{1}, x_{2}, \ldots, x_{k}\right)$, such that the derivatives $\partial \hat{y} / \partial x_{1}$, $\partial \hat{y} / \partial x_{2}, \ldots, \partial \hat{y} / \partial x_{k}$ are simultaneously zero. This value, say $\mathbf{x}_{0}^{\prime}=\left[\mathbf{x}_{1,0}, \mathbf{x}_{2,0}, \ldots, \mathbf{x}_{\mathrm{k}, 0}\right]$, is the stationary point of the fitted surface. So, the derivative of $\hat{y}$ with respect to the vector $\mathbf{x}$, equated to zero, is

$$
\frac{\partial \hat{y}}{\partial x}=\frac{\partial}{\partial x}\left[b_{\sim}+\underset{\sim}{x^{\prime}} \underset{\sim}{b}+\underset{\sim}{x^{\prime}} B \underset{\sim}{x}\right]=\underset{\sim}{b}+\underset{\sim}{2 B x}=0 .
$$

Thus the stationary point is

$$
\mathbf{x}_{0}=-B^{-1} \frac{\mathbf{b}}{2}
$$

Here, the stationary point $\mathbf{x}_{\mathbf{0}}$ (7) can be a point at which the fitted surface attains a maximum or a minimum, or a saddle point. The analysis of the nature of the stationary point begins with a translation of the response function from the origin $\left(x_{1}=0, x_{2}=0, \ldots, x_{k}=0\right)$ to the $\mathbf{x}_{0}$. Figure 1 shows a schematic representation of axis translation for two variables. 
Due to the translation of the axes to stationary point $\mathbf{x}_{\mathbf{0}}$, (4) should be written in terms of the vector, $\mathbf{z}$, given by $\mathbf{z}=$ $\mathbf{x}-\mathbf{x}_{\mathbf{0}}$ :

$$
\begin{aligned}
\hat{y} & =b_{0}+\left(\mathbf{z}^{\prime}+\mathbf{x}_{\mathbf{0}}^{\prime}\right) \mathbf{b}+\left(\mathbf{z}^{\prime}+\mathbf{x}_{\mathbf{0}}^{\prime}\right) B\left(\mathbf{z}+\mathbf{x}_{\mathbf{0}}\right) \\
& =b_{0}+\mathbf{x}_{\mathbf{0}}^{\prime} \mathbf{b}+\mathbf{x}_{\mathbf{0}}^{\prime} B \mathbf{x}_{\mathbf{0}}+\mathbf{z}^{\prime} \mathbf{b}+\mathbf{z}^{\prime} B \mathbf{x}_{\mathbf{0}}+\mathbf{x}_{\mathbf{0}}^{\prime} B \mathbf{z}+\mathbf{z}^{\prime} B \mathbf{z} .
\end{aligned}
$$

Since $\mathbf{z}^{\prime} B \mathbf{x}_{\mathbf{0}}=\mathbf{x}_{\mathbf{0}}^{\prime} B \mathbf{z}$, and since the first three terms represent the response function evaluated at the stationary point, (8) is written as

$$
\hat{y}=\hat{y}_{0}+\mathbf{z}^{\prime}\left(\mathbf{b}+2 B \mathbf{x}_{\mathbf{0}}\right)+\mathbf{z}^{\prime} B \mathbf{z}=y_{0}+\mathbf{z}^{\prime} B \mathbf{z} .
$$

Equation (9) represents the response surface, translated to the new origin. Thus, there is an orthogonal transformation, $\mathbf{z}=M \mathbf{w}$, such that

$$
\mathbf{z}^{\prime} B \mathbf{z}=\mathbf{w}^{\prime} M^{\prime} B M \mathbf{w}=\lambda_{1} w_{1}^{2}+\lambda_{2} w_{2}^{2}+\cdots+\lambda_{k} w_{k}^{2},
$$

where $M$ is the orthogonal matrix $k \times k\left(M^{\prime} M=I_{k}\right)$ and $\lambda_{1}, \lambda_{2}, \ldots, \lambda_{\mathrm{k}}$ are characteristic roots of the matrix $B$. The determination of matrix $M$ is important because the transformation $\mathbf{w}=M^{\prime} \mathbf{z}$ enables one to obtain the expression relating the original variables $\mathbf{z}_{i}$ (as a result $\mathbf{x}_{i}$, since $\mathbf{z}=$ $\mathbf{x}-\mathbf{x}_{\mathbf{0}}$ ) to the canonical one, $\mathbf{w}_{i} . M$ is the matrix of eigenvector associated with the characteristic roots $\lambda_{i}$.

Therefore, based on (9) and (10), the response function can be expressed in terms of new variables $w_{1}, w_{2}, \ldots w_{k}$, whose axes correspond to the principal axes of the contour system. The form of the function in terms of these variables is called the canonical form and is given by

$$
\hat{y}=\hat{y}_{0}+\lambda_{1} w_{1}^{2}+\lambda_{2} w_{2}^{2}+\cdots+\lambda_{k} w_{k}^{2} .
$$

The sign and magnitude of the characteristic roots $\lambda_{i}$ can determine the nature of the stationary point. If $\lambda i<0$, a move in any direction from the stationary point results in a decrease in $\hat{y}$ (see $(11))$. Therefore, the stationary point represents a point of maximum response for the fitted surface. On the other hand, $\lambda_{i}>0, \mathbf{x}_{\mathbf{0}}$ will be a minimum for the fitted surface. Finally, in the case where the $\lambda$ 's differ in sign, the stationary point is a saddle point.

In this work, the canonical analysis was accomplished through a routine implemented using the software Maple 7. The regression parameters of the model (4) were estimated using the software Statistica 7.

\section{Results and Discussion}

3.1. Experimental Results and Fitted Equation. Table 2 shows the central composite experimental design and the results obtained for lactic acid production. The lactic acid concentration varied in a wide range, from $0.45 \mathrm{~g} / \mathrm{L}$ in experiment 26 to $56.88 \mathrm{~g} / \mathrm{L}$ in experiment 12 . The results obtained the central level show good reproducibility.

To obtain the equation that describes the response (lactic acid concentration) as a function of the independent variables, hypothesis tests were performed using the $t$-Student

\begin{tabular}{|c|c|c|c|c|c|}
\hline Run & $\mathrm{LC}(\mathrm{g} / \mathrm{L})$ & $\mathrm{YE}(\mathrm{g} / \mathrm{L})$ & $T\left({ }^{\circ} \mathrm{C}\right)$ & $\mathrm{pH}$ & $\begin{array}{c}\text { Lactic acid } \\
(\mathrm{g} / \mathrm{L})\end{array}$ \\
\hline 1 & 55.0 & 4.37 & 36.0 & 5.0 & 1.67 \\
\hline 2 & 85.0 & 4.37 & 36.0 & 5.0 & 7.20 \\
\hline 3 & 55.0 & 20.37 & 36.0 & 5.0 & 1.28 \\
\hline 4 & 85.0 & 20.37 & 36.0 & 5.0 & 13.50 \\
\hline 5 & 55.0 & 4.37 & 44.0 & 5.0 & 1.12 \\
\hline 6 & 85.0 & 4.37 & 44.0 & 5.0 & 12.87 \\
\hline 7 & 55.0 & 20.37 & 44.0 & 5.0 & 5.67 \\
\hline 8 & 85.0 & 20.37 & 44.0 & 5.0 & 8.46 \\
\hline 9 & 55.0 & 4.37 & 36.0 & 7.0 & 9.90 \\
\hline 10 & 85.0 & 4.37 & 36.0 & 7.0 & 16.38 \\
\hline 11 & 55.0 & 20.37 & 36.0 & 7.0 & 37.08 \\
\hline 12 & 85.0 & 20.37 & 36.0 & 7.0 & 56.88 \\
\hline 13 & 55.0 & 4.37 & 44.0 & 7.0 & 7.20 \\
\hline 14 & 85.0 & 4.37 & 44.0 & 7.0 & 19.58 \\
\hline 15 & 55.0 & 20.37 & 44.0 & 7.0 & 37.80 \\
\hline 16 & 85.0 & 20.37 & 44.0 & 7.0 & 43.65 \\
\hline 17 & 70.0 & 12.37 & 40.0 & 6.0 & 37.22 \\
\hline 18 & 70.0 & 12.37 & 40.0 & 6.0 & 36.94 \\
\hline 19 & 70.0 & 12.37 & 40.0 & 6.0 & 37.15 \\
\hline 20 & 46.8 & 12.37 & 40.0 & 6.0 & 12.87 \\
\hline 21 & 93.2 & 12.37 & 40.0 & 6.0 & 42.13 \\
\hline 22 & 70.0 & 0 & 40.0 & 6.0 & 23.94 \\
\hline 23 & 70.0 & 24.74 & 40.0 & 6.0 & 27.81 \\
\hline 24 & 70.0 & 12.37 & 33.8 & 6.0 & 26.19 \\
\hline 25 & 70.0 & 12.37 & 46.2 & 6.0 & 9.18 \\
\hline 26 & 70.0 & 12.37 & 40.0 & 4.5 & 0.45 \\
\hline 27 & 70.0 & 12.37 & 40.0 & 7.5 & 48.15 \\
\hline
\end{tabular}
statistics to identify the significant parameters. The parameters, estimated by the least-square method, with significance level greater than $10 \%(P>0.1)$ were neglected.
TABLE 2: First central composite design and experimental results.

The fitted equation, in matricial notation, is given by $\left(R^{2}=0.92\right)$

$$
\hat{y}=b_{0}+\mathbf{x}^{\prime} \mathbf{b}+\mathbf{x}^{\prime} B \mathbf{x}
$$

where

$$
\begin{gathered}
\mathbf{x}=\left[\begin{array}{l}
x_{1} \\
x_{2} \\
x_{3} \\
x_{4}
\end{array}\right], \quad \mathbf{b}=\left[\begin{array}{c}
5.57 \\
6.56 \\
0 \\
12.35
\end{array}\right], \\
B=\left[\begin{array}{cccc}
-3.41 & 0 & 0 & 0 \\
0 & -2.99 & 0 & 3.44 \\
0 & 0 & -7.51 & 0 \\
0 & 3.44 & 0 & -4.75
\end{array}\right] .
\end{gathered}
$$

Vector $\mathbf{b}$ shows that the linear effect of temperature was not significant $\left(b_{3}=0\right)$. The only significant interaction occurred between yeast extract concentration and $\mathrm{pH}\left(b_{42} / 2=b_{24} / 2=3.44\right.$, matrix $\left.B\right)$. All quadratic 


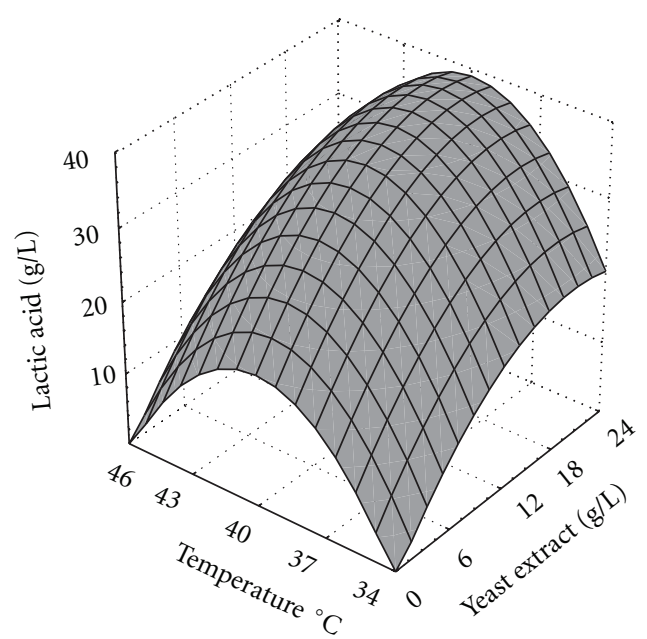

(a)

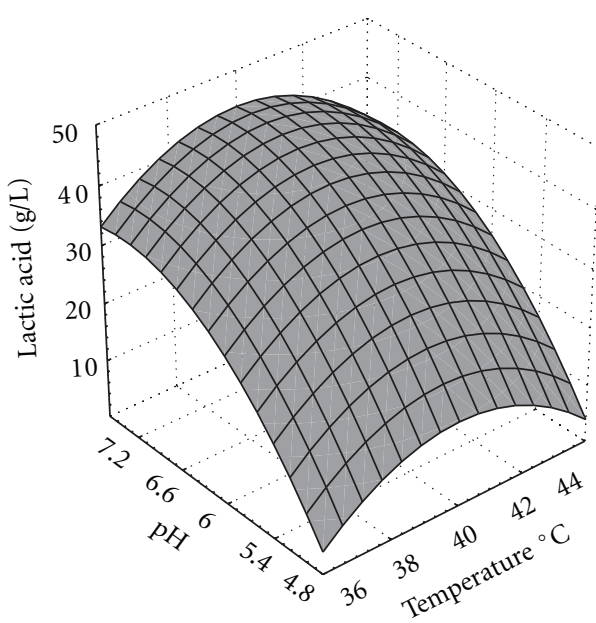

(c)

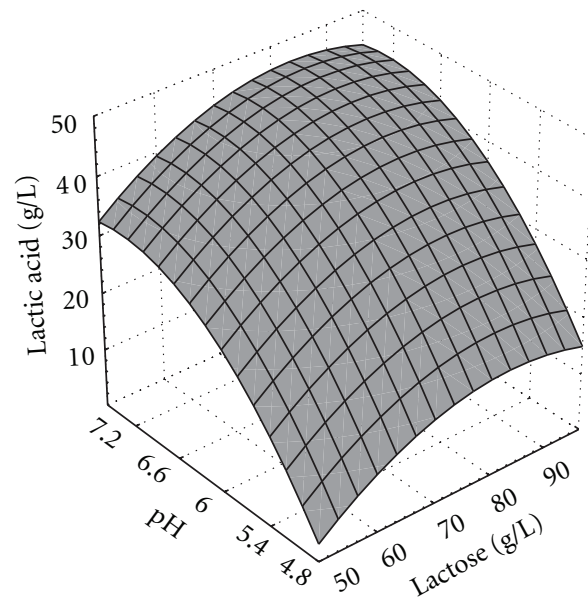

(b)

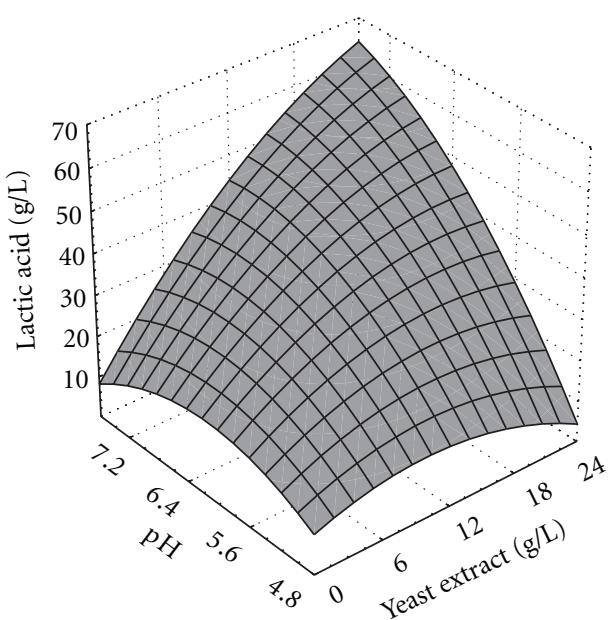

(d)

FIGURE 2: Response surfaces for the production of lactic acid as a function of the variables: (a) temperature and yeast extract concentration; (b) lactose concentration and $\mathrm{pH}$; (c) temperature and $\mathrm{pH}$; (d) yeast extract concentration and $\mathrm{pH}$. For each surface, the other variables are in the center point.

effects, including the temperature, were significant $\left(b_{i i} \neq 0\right.$, matrix $B)$.

The influences of the independent variables and their interactions on the lactic acid concentration can be also analyzed through the response surfaces (Figure 2) obtained from (11). The production of lactic acid was maximum when the temperature was around $40^{\circ} \mathrm{C}\left(x_{3}=0\right)$, as it can be seen in Figures 2(a) and 2(c). The effect of temperature on the production of lactic acid by Lactobacilli has only been studied in a few reports [11]. Lactobacilli are mesophilic, which makes plausible the result obtained in this work, although some strains of Lactobacillus helveticus grow at 50$52^{\circ} \mathrm{C}[22]$. The fact that the optimum temperature is close to $40^{\circ} \mathrm{C}$ can be considered acceptable when compared with the works available in the literature using cheese whey as substrate and strains of Lactobacillus helveticus. Tango and Ghaly [18], while studying the effect of temperature on product formation, performed experiments at $23^{\circ} \mathrm{C}, 37^{\circ} \mathrm{C}$, and $42^{\circ} \mathrm{C}$. The highest concentration of lactic acid was obtained at $42^{\circ} \mathrm{C}$. Kulozik and Wilde [23] performed experiments at five levels of temperature: $35^{\circ} \mathrm{C}, 38^{\circ} \mathrm{C}, 42^{\circ} \mathrm{C}, 45^{\circ} \mathrm{C}$, and $49^{\circ} \mathrm{C}$. The product formation was slightly higher at $45^{\circ} \mathrm{C}$ than at $42^{\circ}$ C. Norton et al. [24], Amrane and Prigent [25], and Schepers et al. [26] used a temperature of $42^{\circ} \mathrm{C}$ in their work, which corroborates the results obtained here, although they do not justify their choices.

Figure 2(b) shows that the lactic acid concentration was maximum when the lactose concentration was in the range of $70-85 \mathrm{~g} / \mathrm{L}\left(0<x_{1}<1\right)$. The response decreased for larger concentrations, probably due to the inhibition by the substrate. Several studies showed that cellular growth and lactic acid production by bacteria of the Lactobacillus genus are inhibited by the substrate [27, 28]. Tango and Ghaly [29] report that the growth of Lactobacillus helveticus and the production of lactic acid were inhibited for lactose concentrations greater than $80 \mathrm{~g} / \mathrm{L}$, which confirms 
the results of this work. However, Aeschlimann and von Stockar [30] published a similar study where there was no inhibition by the substrate for initial lactose concentrations smaller than $132 \mathrm{~g} / \mathrm{L}$.

The strong influence of the $\mathrm{pH}$ on the process can be seen in Figures 2(b) and 2(c). The amount of lactic acid produced when the $\mathrm{pH}$ was smaller than $6\left(x_{4}<0\right)$ was very little. The major influence of $\mathrm{pH}$ over lactic acid production in fermentation processes is due to the fact that the catalytic activity of the enzymes and metabolic activity of the microorganism depend on extracellular $\mathrm{pH}$. According to Hofvendahl and Hahn-Hägerdal [11] and Wood and Holzapfel [22], optimal $\mathrm{pH}$ for lactic acid production by lactic acid bacteria varies between 5.0 and 7.0 and is dependent on the strain.

For values of $\mathrm{pH}$ equal or larger than $6\left(x_{4}>0\right)$, there was higher production of lactic acid, except when the yeast extract concentration was smaller than $12.37 \mathrm{~g} / \mathrm{L}\left(x_{2}<0\right)$. That interaction between $\mathrm{pH}$ and yeast extract is shown in Figure 2(d). Even in favorable conditions of $\mathrm{pH}$, low concentrations of yeast extract led to low product concentrations. This happened due to the complex nutritional demands of the genus Lactobacillus [22]. The source of nitrogen is the main factor influencing the growth of these microorganisms. Because the fermentative production of lactic acid is associated to the cellular growth, there is no product yield if the medium does not have an appropriate concentration of nitrogen to promote growth [31]. According to Figure 2(a), the optimum concentration of yeast extract seems to be in the range from $20.37 \mathrm{~g} / \mathrm{L}$ to $24.74 \mathrm{~g} / \mathrm{L}\left(1<x_{2}<1.55\right)$. This result is in accordance with Amrane and Prigent [25]. They carried out a study on the influence of the yeast extract concentration on the homolactic fermentation of cheese whey, using Lactobacillus helveticus. The experiments used yeast extract concentrations in the range 2-30 g/L. According to the authors, larger concentrations of this substance led to the same final concentration of lactic acid; however, the fermentation time decreased significantly. In this work, the production of lactic acid was very low at concentrations of yeast extract smaller than $12.37 \mathrm{~g} / \mathrm{L}$, for the fermentation time chosen for that study. Several authors have been looking for low cost nitrogen sources substitutes for yeast extract. Corn steep liquor seems to be a viable alternative [32-34]. Fungi and yeasts $[8,35]$ and adapted strains of Lactobacillus [29] have also been used with the same purpose.

3.2. Canonical Analysis. The point of maximum lactic acid concentration was determined through a canonical analysis of the fitted model (12). The stationary point $\left(\mathbf{x}_{\mathbf{0}}\right)$ obtained from (6) is given by

$$
\mathbf{x}_{\mathbf{0}}=\left[\begin{array}{c}
0.82 \\
15.54 \\
0 \\
12.56
\end{array}\right]
$$

TABLE 3: Coded and actual values of variables in the second central composite design.

\begin{tabular}{llllll}
\hline & & \multicolumn{3}{c}{$X_{i}$} & \\
& -1.40 & -1 & 0 & 1 & 1.40 \\
\hline $\begin{array}{l}\text { YE (yeast extract } \\
\text { concentration, g/L) }\end{array}$ & 18.36 & 20 & 24 & 28 & 29.64 \\
pH & 5.6 & 6 & 7 & 8 & 8.4 \\
\hline
\end{tabular}

The characteristic roots $\left(\lambda_{i}\right)$ of matrix $B(11)$ are all negative: $\lambda_{1}=-7.51, \lambda_{2}=-7.42, \lambda_{3}=-3.41, \lambda_{4}=-0.32$. Therefore, $\mathbf{x}_{\mathbf{0}}$ is a point of maximum response.

From stationary point (12), it can be seen that the optimum coded value obtained for lactose concentration was $x_{1}=0.82$; this value corresponds to $82.3 \mathrm{~g} / \mathrm{L}$ (see $(1)$ ). There are no reports about the ideal concentration of this substrate in the fermentative production of lactic acid using Lactobacillus helveticus. In works published on this subject, initial concentrations were in the range 50-150 g/L. Increases of the initial concentration of lactose to values greater than $100 \mathrm{~g} / \mathrm{L}$ implied in greater product concentrations [26]. However, they caused a decrease of conversion from substrate to product $\mathrm{Y}_{\mathrm{P} / \mathrm{S}}$ and, consequently, an increase in the concentration of residual lactose. Therefore, the value found in the present work can be considered plausible. The optimum coded value obtained for temperature was $x_{3}=0$, corresponding to $40^{\circ} \mathrm{C}$ (2), confirming the value indicated by the response surface analysis (Figures 2(a) and 2(c)).

The optimum values of yeast extract concentration $\left(x_{2}=\right.$ 15.54) and of $\mathrm{pH}\left(x_{4}=12.56\right)$ extrapolated the limits of the experimental design $(-1.55$ to +1.55$)$. Hence, a new experimental design had to be performed to find the best conditions for these two variables. In this new experimental design, the lactose concentration and temperature were set at the best conditions, that is, $82 \mathrm{~g} / \mathrm{L}$ and $40^{\circ} \mathrm{C}$, respectively. The coded variables for this second central composite design were defined as

$$
\begin{gathered}
x_{2}=\frac{\mathrm{YE}(\mathrm{g} / \mathrm{L})-24 \mathrm{~g} / \mathrm{L}}{4 \mathrm{~g} / \mathrm{L}}, \\
x_{4}=\mathrm{pH}-7 .
\end{gathered}
$$

The coded and actual levels of these variables are in Table 3. The results of the new experimental design are showed in Table 4.

As before, an empirical equation was fitted to this new set of experimental data. The fitted equation $\left(R^{2}=0.95\right)$ in matricial notation is given by

$$
\mathbf{x}=\left[\begin{array}{l}
x_{2} \\
x_{4}
\end{array}\right], \quad \mathbf{b}=\left[\begin{array}{c}
0 \\
-6.77
\end{array}\right], \quad B=\left[\begin{array}{cc}
-0.16 & -0.05 \\
-0.05 & -0.06
\end{array}\right] .
$$

The response surface corresponding to this new equation is shown in Figure 3. The production of lactic acid was very small both for $\mathrm{pH}$ greater than $8\left(x_{4}>1\right)$ and for yeast extract concentrations larger than $28 \mathrm{~g} / \mathrm{L}\left(x_{2}>1\right)$. On the other hand, the product concentration was maximum for yeast 
TABLE 4: New central composite design and experimental results.

\begin{tabular}{lcc}
\hline YE $(\mathrm{g} / \mathrm{L})$ & $\mathrm{pH}$ & Lactic acid $(\mathrm{g} / \mathrm{L})$ \\
\hline 20 & 6 & 42.15 \\
28 & 6 & 26.32 \\
20 & 8 & 6.80 \\
28 & 8 & 39.82 \\
24 & 7 & 58.23 \\
24 & 7 & 59.14 \\
18.36 & 7 & 48.73 \\
29.64 & 7 & 38.04 \\
24 & 5.6 & 28.02 \\
24 & 8.4 & 5.20 \\
\hline
\end{tabular}

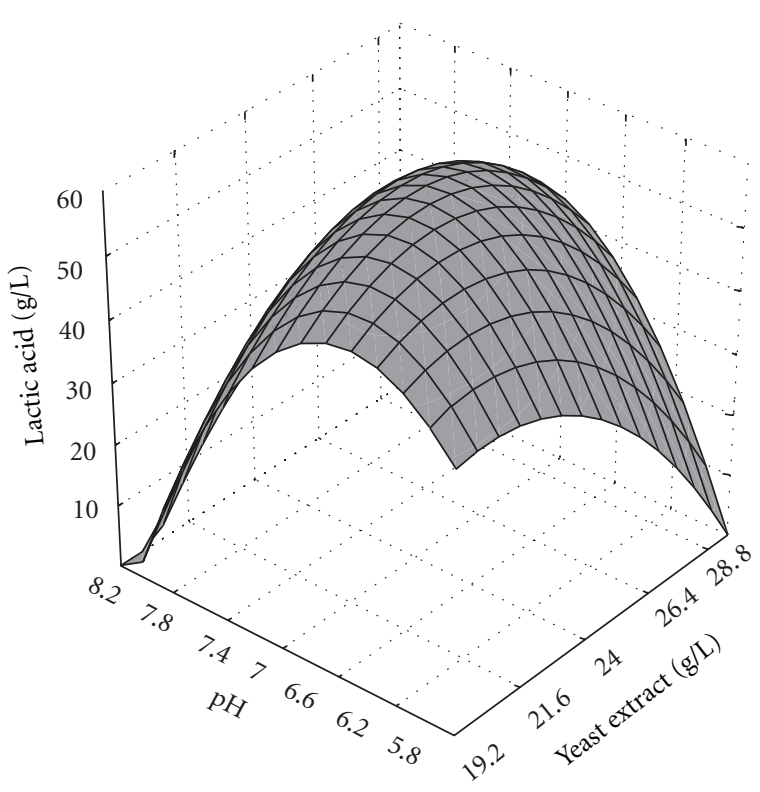

Figure 3: Response surface for lactic acid production as a function of the $\mathrm{pH}$ and of the yeast extract concentration $\left(T=40^{\circ} \mathrm{C}\right.$, lactose $82 \mathrm{~g} / \mathrm{L})$.

extract concentrations in the range $20-24 \mathrm{~g} / \mathrm{L}\left(0<X_{2}<1\right)$ and $\mathrm{pH}$ around $7\left(x_{4}=0\right)$.

The point of maximum response was determined through a canonical analysis of the fitted model. The stationary point is given by

$$
\mathbf{x}_{0}=\left[\begin{array}{l}
-0.16 \\
-0.20
\end{array}\right] .
$$

The actual values of the coded independent variables were obtained from (15). The coded variables $x_{2}=-0.16$ and $x_{4}=-0.20$ correspond to $23.36 \mathrm{~g} / \mathrm{L}$ of yeast extract concentration and $\mathrm{pH}$ 6.8, respectively. With the new stationary point, the canonical form of the fitted model is given by

$$
Y=59.38-23.79 w_{2}^{2}-5.61 w_{4}^{2}
$$

This equation shows that both characteristic roots $\left(\lambda_{i}\right)$ have negative sign. This means that any displacement from

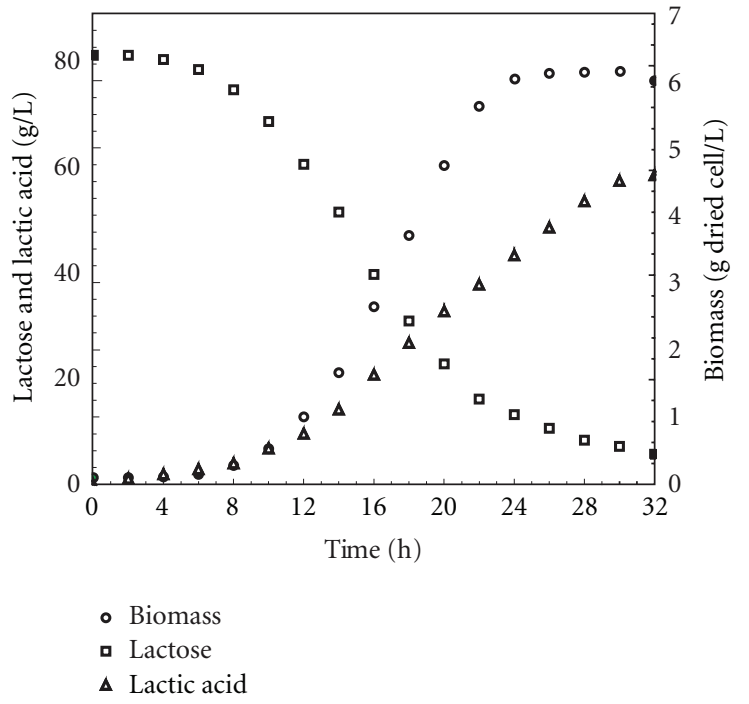

Figure 4: Concentrations of product, substrate, and biomass as a function of the time, under the best conditions (lactose $82 \mathrm{~g} / \mathrm{L}$; yeast extract $23.36 \mathrm{~g} / \mathrm{L}$; temperature $40^{\circ} \mathrm{C}$; $\mathrm{pH} 6.8$ ).

the stationary point causes a decrease of the response and, therefore, the stationary point is a maximum point. As a result, the optimum conditions determined by this study are temperature $40^{\circ} \mathrm{C}, \mathrm{pH} 6.8$, concentration of lactose $82 \mathrm{~g} / \mathrm{L}$, and concentration of yeast extract $23.36 \mathrm{~g} / \mathrm{L}$. Under these conditions, the canonical analysis predicts a production of acid lactic of $59.38 \mathrm{~g} / \mathrm{L}$.

A new fermentation was accomplished using the optimum operational conditions listed above. The result is shown in Figure 4. The concentration of lactic acid reached $59.15 \mathrm{~g} / \mathrm{L}$, confirming the result predicted by the canonical analysis. This value is the biggest ever reported in the literature for works that used cheese whey as substrate and strains of Lactobacillus helveticus ATCC 15009. The low residual concentration of the lactose, $5.75 \mathrm{~g} / \mathrm{L}$, shows that the substrate was almost totally consumed after 32 hours of fermentation. The cellular concentration reached the maximum value of $6.14 \mathrm{~g} / \mathrm{L}$. The factors of conversion from substrate into product $\mathrm{Y}_{\mathrm{P} / \mathrm{S}}$ and from substrate into biomass $\mathrm{Y}_{\mathrm{X} / \mathrm{S}}$ were 0.77 and 0.08 , respectively.

\section{Conclusions}

This study demonstrated that the response surface methodology associated with the canonical analysis was appropriate to find the conditions that maximized the production of lactic acid from cheese whey fermentation. The optimal conditions determined by the canonical analysis were $40^{\circ} \mathrm{C}, \mathrm{pH}$ $6.8,82 \mathrm{~g} / \mathrm{L}$ of lactose, and $23.36 \mathrm{~g} / \mathrm{L}$ of yeast extract. At this point, the lactic acid concentration reached $59.15 \mathrm{~g} / \mathrm{L}$, the biggest value ever reported in studies using cheese whey as substrate and strains of Lactobacillus helveticus ATCC 15009 in batch fermentation.

The production of lactic acid was strongly linked to the $\mathrm{pH}$ and to the yeast extract concentration. The decrease of 
the response for higher lactose concentrations indicates an inhibition by the substrate.

The high concentration of yeast extract at the point of maximum response justifies the search for low cost nitrogen sources.

\section{References}

[1] S. T. Yang, H. Zhu, Y. Li, and G. Hong, "Continuous propionate production from whey permeate using a novel fibrous bed bioreactor," Biotechnology and Bioengineering, vol. 43, no. 11, pp. 1124-1130, 1994.

[2] A. J. Mawson, "Bioconversions for whey utilization and waste abatement," Bioresource Technology, vol. 47, no. 3, pp. 195203, 1994.

[3] F. V. Kosikowski, "Whey utilization and whey products," Journal of Dairy Science, vol. 62, pp. 1149-1160, 1979.

[4] T. Sienkiewicz and C. L. Riedel, Whey and Whey Utilization, Verlag Th. Mann, Germany, 1990.

[5] M. I. González Siso, "The biotechnological utilization of cheese whey: a review," Bioresource Technology, vol. 57, no. 1, pp. 1-11, 1996.

[6] W. Fu and A. P. Mathews, "Lactic acid production from lactose by Lactobacillus plantarum: kinetic model and effects of $\mathrm{pH}$, substrate, and oxygen," Biochemical Engineering Journal, vol. 3, no. 3, pp. 163-170, 1999.

[7] R. Datta, S. P. Tsai, P. Bonsignore, S. H. Moon, and J. R. Frank, "Technological and economic potential of poly(lactic acid) and lactic acid derivatives," FEMS Microbiology Reviews, vol. 16, no. 2-3, pp. 221-231, 1995.

[8] M. T. Gao, T. Shimamura, N. Ishida, and H. Takahashi, "Fermentative lactic acid production with a metabolically engineered yeast immobilized in photo-crosslinkable resins," Biochemical Engineering Journal, vol. 47, no. 1-3, pp. 66-70, 2009.

[9] X. Liu, L. Smith, G. Wei, Y. Won, and P. X. Ma, "Surface engineering of nano-fibrous poly(L-lactic acid) scaffolds via self-assembly technique for bone tissue engineering," Journal of Biomedical Nanotechnology, vol. 1, no. 1, pp. 54-60, 2005.

[10] G. Bustos, A. B. Moldes, J. L. Alonso, and M. Vázquez, "Optimization of D-lactic acid production by Lactobacillus coryniformis using response surface methodology," Food Microbiology, vol. 21, no. 2, pp. 143-148, 2004.

[11] K. Hofvendahl and B. Hahn-Hägerdal, "Factors affecting the fermentative lactic acid production from renewable resources," Enzyme and Microbial Technology, vol. 26, no. 2-4, pp. 87-107, 2000.

[12] M. Hujanen, S. Linko, Y. Y. Linko, and M. Leisola, "Optimisation of media and cultivation conditions for $\mathrm{L}(+)(\mathrm{S})$-lactic acid production by Lactobacillus casei NRRL B-441," Applied Microbiology and Biotechnology, vol. 56, no. 1-2, pp. 126-130, 2001.

[13] S. J. Téllez-Luis, A. B. Moldes, J. L. Alonso, and M. Vázquez, "Optimization of lactic acid production by Lactobacillus delbrueckii through response surface methodology," Journal of Food Science, vol. 68, no. 4, pp. 1454-1458, 2003.

[14] B. J. Naveena, M. Altaf, K. Bhadrayya, S. S. Madhavendra, and G. Reddy, "Direct fermentation of starch to L(+) lactic acid in SSF by Lactobacillus amylophilus GV6 using wheat bran as support and substrate: medium optimization using RSM," Process Biochemistry, vol. 40, no. 2, pp. 681-690, 2005.

[15] J. F. Hair, R. L. Tatham, R. E. Anderson, and W. Black, Multivariate Data Analysis, Prentice Hall, New York, NY, USA, 5th edition, 1998.
[16] M. C. B. Fortes, A. A. M. Silva, R. C. Guimarães, C. H. Ataíde, and M. A. S. Barrozo, "Pre-separation of siliceous gangue in apatite flotation," Industrial and Engineering Chemistry Research, vol. 46, no. 21, pp. 7027-7029, 2007.

[17] R. C. Santana, A. C. C. Farnese, M. C. B. Fortes, C. H. Ataíde, and M. A. S. Barrozo, "Influence of particle size and reagent dosage on the performance of apatite flotation," Separation and Purification Technology, vol. 64, no. 1, pp. 8-15, 2008.

[18] M. S. A. Tango and A. E. Ghaly, "Effect of temperature on lactic acid production from cheese whey using Lactobacillus helveticus under batch conditions," Biomass and Bioenergy, vol. 16, no. 1, pp. 61-78, 1999.

[19] C. F. J. Wu and M. Hamada, Experiments: Planning, Analysis, and Parameter Design Optimization, John Wiley \& Sons, New York, NY, USA, 2000.

[20] J. de Man, M. Rogosa, and M. Sharpe, "A medium for the cultivation of Lactobacilli," Journal of Applied Bacteriology, vol. 23, no. 1, pp. 130-135, 1960.

[21] G. L. Miller, "Use of dinitrosalicylic acid reagent for determination of reducing sugar," Analytical Chemistry, vol. 31, no. 3, pp. 426-428, 1959.

[22] B. J. B. Wood and W. H. Holzapfel, The Genera of Lactic Acid Bacteria, Blackie Academic \& Professional, Glasgow, UK, 1995.

[23] U. Kulozik and J. Wilde, "Rapid lactic acid production at high cell concentrations in whey ultrafiltrate by Lactobacillus helveticus," Enzyme and Microbial Technology, vol. 24, no. 5-6, pp. 297-302, 1999.

[24] S. Norton, C. Lacroix, and J. C. Vuillemard, "Kinetic study of continuous whey permeate fermentation by immobilized Lactobacillus helveticus for lactic acid production," Enzyme and Microbial Technology, vol. 16, no. 6, pp. 457-466, 1994.

[25] A. Amrane and Y. Prigent, "Influence of yeast extract concentration on batch cultures of Lactobacillus helveticus: growth and production coupling," World Journal of Microbiology and Biotechnology, vol. 14, no. 4, pp. 529-534, 1998.

[26] A. W. Schepers, J. Thibault, and C. Lacroix, "Lactobacillus helveticus growth and lactic acid production during $\mathrm{pH}$ controlled batch cultures in whey permeate/yeast extract medium. Part I. Multiple factor kinetic analysis," Enzyme and Microbial Technology, vol. 30, no. 2, pp. 176-186, 2002.

[27] C. N. Burgos-Rubio, M. R. Okos, and P. C. Wankat, "Kinetic study of the conversion of different substrates to lactic acid using Lactobacillus bulgaricus," Biotechnology Progress, vol. 16, no. 3, pp. 305-314, 2000.

[28] H. Mi-Young, S. Kim, Y. Lee, M. Kim, and S. Kim, "Kinetics analysis of growth and lactic acid production in $\mathrm{pH}$-controlled batch cultures of Lactobacillus casei KH-1 using yeast extract/ corn steep liquor/glucose medium," Journal of Bioscience and Bioengineering, vol. 96, no. 2, pp. 134-140, 2003.

[29] M. S. A. Tango and A. E. Ghaly, "Kinetic modeling of lactic acid production from batch submerged fermentation of cheese whey," Transactions of the American Society of Agricultural Engineers, vol. 42, no. 6, pp. 1791-1800, 1999.

[30] A. Aeschlimann and U. von Stockar, "The production of lactic acid from whey permeate by Lactobacillus helveticus," Biotechnology Letters, vol. 11, no. 3, pp. 195-200, 1989.

[31] G. G. Pritchard and T. Coolbear, "The physiology and biochemistry of the proteolytic system in lactic acid bacteria," FEMS Microbiology Reviews, vol. 12, no. 1-3, pp. 179-206, 1993.

[32] M. Altaf, B. J. Naveena, and G. Reddy, "Use of inexpensive nitrogen sources and starch for $1(+)$ lactic acid production in anaerobic submerged fermentation," Bioresource Technology, vol. 98, no. 3, pp. 498-503, 2007. 
[33] B. Gullón, J. L. Alonso, and J. C. Parajó, “Experimental evaluation of alternative fermentation media for L-lactic acid production from apple pomace," Journal of Chemical Technology and Biotechnology, vol. 83, no. 5, pp. 609-617, 2008.

[34] L. Yu, T. Lei, X. Ren, X. Pei, and Y. Feng, "Response surface optimization of 1-(+)-lactic acid production using corn steep liquor as an alternative nitrogen source by Lactobacillus rhamnosus CGMCC 1466," Biochemical Engineering Journal, vol. 39, no. 3, pp. 496-502, 2008.

[35] V. Kitpreechavanich, T. Maneeboon, Y. Kayano, and K. Sakai, "Comparative characterization of 1-Lactic acid-producing thermotolerant Rhizopus Fungi," Journal of Bioscience and Bioengineering, vol. 106, no. 6, pp. 541-546, 2008. 

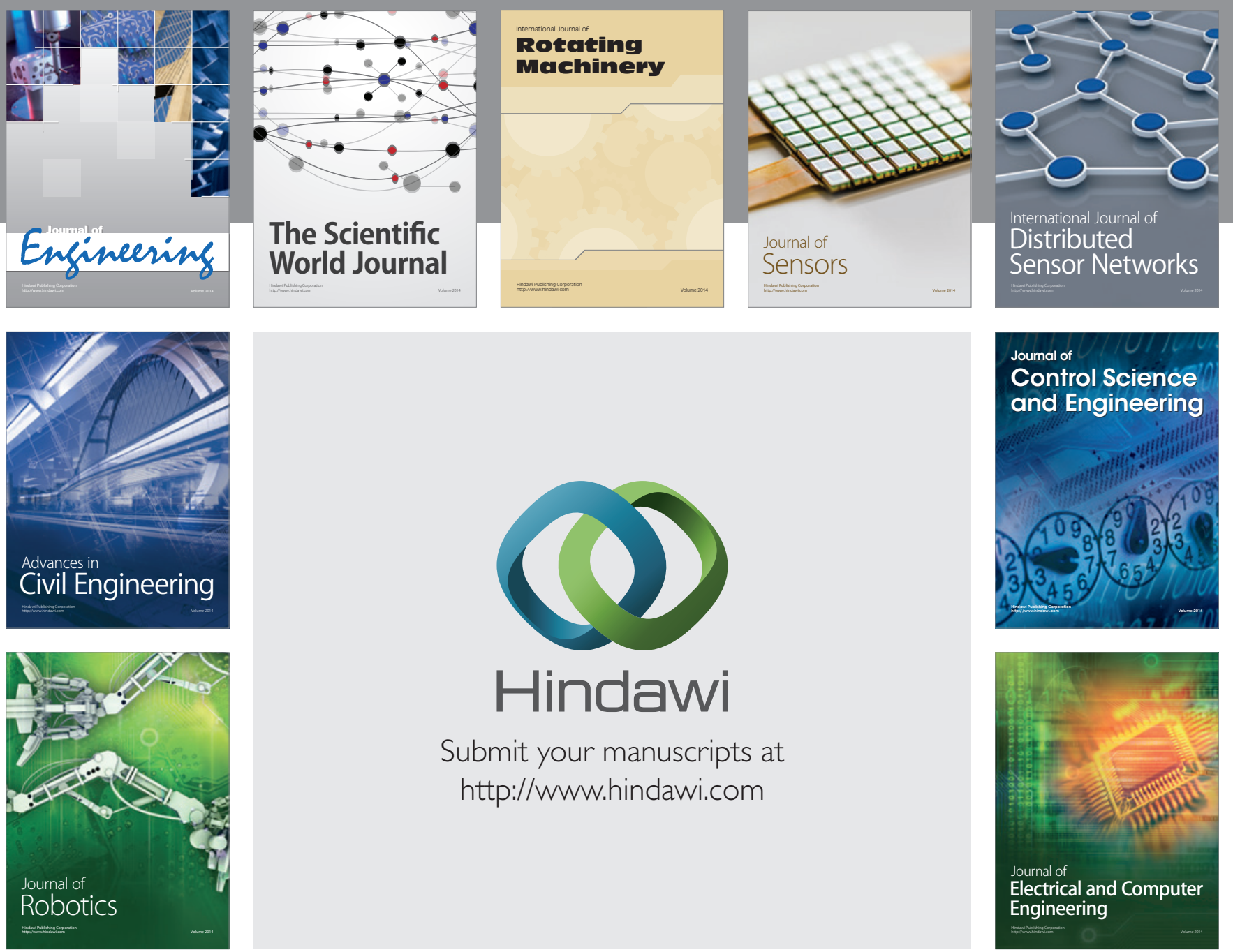

Submit your manuscripts at

http://www.hindawi.com
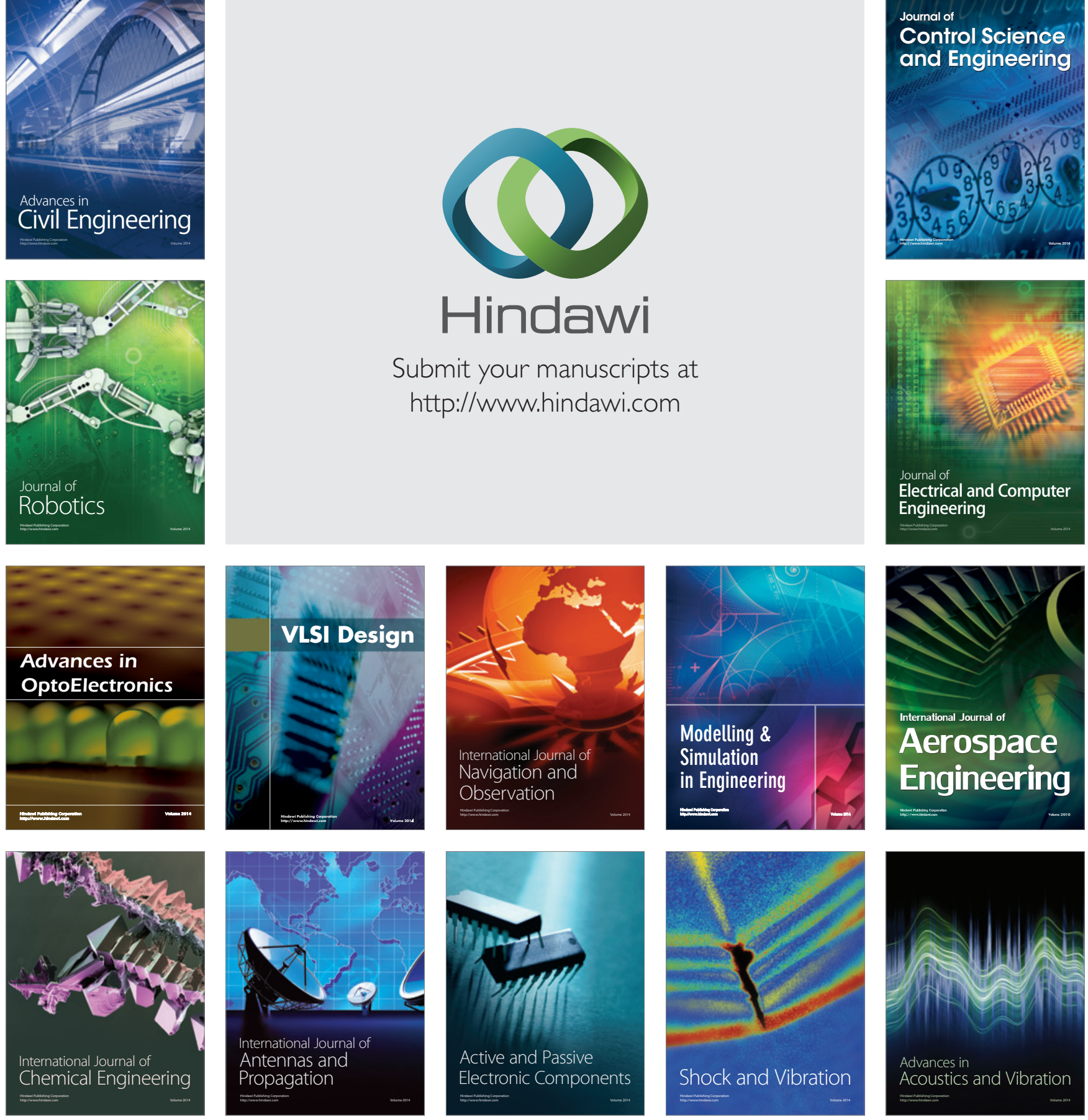